\title{
Environmental filtering and spatial processes equally contributed to macroinvertebrate metacommunity dynamics in the highly urbanized river networks in Shenzhen, South China
}

Zhenyuan Liu ${ }^{1,2}$, Tingting Zhou ${ }^{1,2}$, Yongde Cui ${ }^{1}$, Zhengfei Li ${ }^{1}$, Weimin Wang ${ }^{3}$, Yushun Chen ${ }^{1 *}$ and Zhicai Xie ${ }^{1 *}$

\begin{abstract}
Background: Disentangling the relative roles of environmental filtering and spatial processes in structuring ecological communities is a central topic in metacommunity ecology. Metacommunity ecology in the temperate river ecosystems has been well developed, while less attention has been paid to subtropical urban river networks. Here, we examined the ecological factors and seasonal difference in structuring macroinvertebrates metacommunity assembly in the subtropical urban river networks in Shenzhen, South China.

Results: Our results revealed that there was no significant distinction of macroinvertebrate community composition among seasons, with only the relative abundance of Mollusca and Odonata significantly differed in both wet and dry seasons. One possible explanation was that most macroinvertebrates are generally pollution-tolerant taxa characterized with nonseasonal life cycle. In addition, distance-based redundancy analysis and variation partitioning approach revealed that metacommunity was determined equally by the environmental and dispersal-related factors. Further, our results showed that, although a slight temporal variation of relative contribution, the identity and explanation power of ecological factors were different among seasons. Specifically, stronger environmental filtering structuring community dynamics was observed in the dry than wet seasons, which might be owing to higher environmental heterogeneity under a low water-flow condition. Moreover, we detected that the influence of spatial processes was stronger in the wet than dry seasons, indicating an obvious dispersal processes due to high connectivity among sites.

(Continued on next page)
\end{abstract}

\footnotetext{
* Correspondence: yushunchen@ihb.ac.cn; zhcxie@ihb.ac.cn

'Institute of Hydrobiology, Chinese Academy of Sciences, Wuhan 430072,

Hubei, China

Full list of author information is available at the end of the article
}

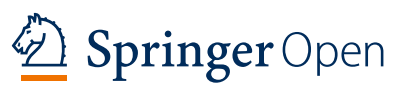

(c) The Author(s). 2021 Open Access This article is licensed under a Creative Commons Attribution 4.0 International License which permits use, sharing, adaptation, distribution and reproduction in any medium or format, as long as you give appropriate credit to the original author(s) and the source, provide a link to the Creative Commons licence, and indicate if changes were made. The images or other third party material in this article are included in the article's Creative Commons licence, unless indicated otherwise in a credit line to the material. If material is not included in the article's Creative Commons licence and your intended use is not permitted by statutory regulation or exceeds the permitted use, you will need to obtain permission directly from the copyright holder. To view a copy of this licence, visit http://creativecommons.org/licenses/by/4.0/. 


\begin{abstract}
(Continued from previous page)
Conclusion: Overall, our results revealed that environmental and spatial factors equally explained variations of macroinvertebrate metacommunity, implying the necessity of considering dispersal-related processes structuring ecological communities in river bioassessment programs. Moreover, degraded habitat conditions and water quality were the predominant factors that affected macroinvertebrate communities, indicating the significance and feasibility of improving local abiotic conditions to sustain local biodiversity. Further, our findings revealed the importance of seasonal dynamics of these urban river networks in structuring macroinvertebrate metacommunity. Thereby, our study improves the understanding of ecological processes governing macroinvertebrate metacommunity and underlines the idea that community ecology studies should go beyond the single snapshot survey in river networks.
\end{abstract}

Keywords: Community assembly, Seasonal variation, Macroinvertebrate metacommunity, Environmental filtering, Spatial processes, Urban river

\section{Introduction}

Disentangling the underlying processes driving spatialtemporal variations of ecological communities is a major topic in modern community ecology (Chase et al. 2020; Chase and Myers 2011; Cottenie 2005). Two primary processes have been proposed to explain the mechanisms governing ecological communities (Chase 2003; Tonkin et al. 2016). The niche-based deterministic processes (e.g., environmental filtering and biological interactions within and among species) assumes that species coexistence is premised on the differentiation of ecological niches (Keddy 1992). In this case, species sharing similar functional traits should occupy similar environments (Carvalho et al. 2019). Besides, stochastic processes assumes that there is no ecological differentiation between species, and it is believed that spatial factors (e.g., related to species dispersal) are important in structuring community assembly (Chave 2004; Hubbell and Borda-De-Agua 2004). Recently, metacommunity theory provides a comprehensive framework that integrating both environmental filtering and dispersal-related processes explaining divergence among community composition across scales of space and time (Chase et al. 2020; Leibold et al. 2004). Theoretical and empirical research suggest that both basic processes should be jointly responsible for the variations in community composition, but the relative roles of these processes may depend largely on ecosystem types (Logue et al. 2011), seasonal dynamics (Chen et al. 2019; Csercsa et al. 2018; Li et al. 2020), and focal biological groups (He et al. 2020; Schmera et al. 2016; Wang et al. 2020).

Urban rivers possess many attributes that make them ideal natural systems for studying the relative contribution of environmental filtering and dispersal processes for aquatic organisms (Shu et al. 2020). As a highly disturbed ecosystem, urban rivers exhibited strong environmental gradients due to a series of anthropogenic stressors, such as nutrient enrichment, elevated temperature, and altered instream substrate composition (Allan 2004; Luo et al. 2018; Wang et al. 2018). These strong environmental gradients can serve as environmental filters to regulate community structure and diversity (Castro et al. 2018), which increased the strength of deterministic processes governing aquatic metacommunity. Besides, river hydrological alterations (e.g., altered macrosystem dynamics and damming) would limit the processes of organism dispersal via damming and humanities building (Raabe and Hightower 2014; Wan et al. 2018). These disturbances could cause rapid and difficult-to-reverse ecological changes that impede the delivery of ecosystem services (Isabwe et al. 2018). However, the mechanisms underlying ecological communities in highly urbanized city river networks remain unclear (Bourassa et al. 2017; Gál et al. 2019).

Recent studies have frequently emphasized that mechanisms governing community assembly in river systems varied among seasons (Chen et al. 2019; Fernandes et al. 2013; Li et al. 2020). Ecosystems are dynamic, especially for subtropical rivers, even on a relatively short time scale (Datry et al. 2016). In this case, seasonality is a crucial driver of environmental heterogeneity and connectivity among habitats (Fernandes et al. 2014; Vanschoenwinkel et al. 2010). For instance, in the wet season, high flow has increased locations connection and is beneficial for aquatic organisms expanding their ranges into adjacent locations (Sarremejane et al. 2017a). In this regard, spatial signal of community would be expected to enhance due to sufficient dispersal under high connectivity (Cottenie et al. 2003). Besides, snapshot surveys may misrepresent the relative contribution of specific processes of community assembly, because they assumed that the mechanism governing community variations is stable through time (Csercsa et al. 2018; Li et al. 2020). Thus, teasing apart the seasonal difference of these basic processes would provide more detailed information for understanding the mechanisms of community assembly.

To our knowledge, the community assembly mechanisms were well developed in temperate river ecosystems (Cilleros et al. 2017); however, for subtropical urban river networks, this knowledge is still poorly understood (Chen et al. 2019). Moreover, testing seasonal difference 
of these processes in subtropical river ecosystems are still lacking (Chen et al. 2019; Isabwe et al. 2018; Li et al. 2020). In this study, we selected macroinvertebrtae, a widely used ecological indicator in environmental monitoring and bioassessment programs (Rosenberg and Resh 1993), as the model organisms to understand the mechanisms of community assembly and the seasonal shifts of the involved mechanisms (Wang et al. 2020). Here, we tested the following three predictions. First, macroinvertebrate community assembly would be primarily determined by environmental filtering under harsh conditions, because intensive anthropogenic stressors can constitute a strict environmental filter to select particular organisms (Chase 2007). Second, we predicted a higher biodiversity and stronger environmental filtering structuring community assembly in the dry than wet season because higher habitat heterogeneity in the dry season would provide more niches for macroinvertebrtae (Sarremejane et al. 2017a). Third, we hypothesized that spatial processes governing community assembly was stronger in the wet than dry seasons due to a stronger dispersal effect induced by higher connectivity (Fernandes et al. 2013).

\section{Methods}

\section{Study area and sampling sites}

The present study was conducted in Shenzhen $\left(113^{\circ}\right.$ $43^{\prime}-114^{\circ} 38^{\prime} \mathrm{E}, 22^{\circ} 24^{\prime}-22^{\circ} 52^{\prime} \mathrm{N}$ ), a coastal megacity located in the Southeast part of China. This city area comprises approximately $1997 \mathrm{~km}^{2}$ and with 13 million inhabitants in 2019 (Shenzhen Statistical Yearbook 2019). Shenzhen is characterized by a subtropical monsoon climate, with an average annual temperature of 24 ${ }^{\circ} \mathrm{C}$ and an average annual precipitation of $1882 \mathrm{~mm}$. The precipitation of Shenzhen has a great seasonal fluctuations, with $96.3 \%$ of rain fall concentrated during the wet season (April to September) (Shenzhen Climate Bulletin 2019). Specifically, due to the fact that main watersheds in Shenzhen are typical rain-source urban rivers, river runoff and flow volumes are closely linked to precipitation (Liu et al. 2019).

Shenzhen has experienced enormous urbanization development and has grown to be one of the flourishing cities in the last four decades (Qian et al. 2020). Besides, due to rapidly developing economy, intensive anthropogenic activities and insufficient wastewater treatment plant, rivers in Shenzhen have suffered a series of environmental pollution problems, such as ecosystem health deterioration (Ng et al. 2011), water quality degradation (Liu et al. 2019), etc. However, macroinvertebrate community patterns and the mechanisms underlying community assembly in this region received far less attention.

In this study, a total of 62 sampling sites were sampled in August (wet season) and December (dry season) in 2019 (Fig. 1). These sites were roughly evenly distributed in Maozhouhe River (MZHR: 12 sites), Guanlanhe River (GLHR: 13 sites), Shenzhenhe River (SZHR: 13 sites), Pingshanhe River (PSHR: 12 sites), and Dapenghe River (DPHR: 12 sites).

\section{Macroinvertebrate sampling and identification}

At each sampling site, we refer to a multi-habitat sampling technique in the field, with five replicates randomly sampled along a 100-m-long stretch reach (Barbour et al. 1999). The main habitats were selected, including different substrate (i.e., cobble, pebble, gravel, and sand and silt), riparian zone, and submerged macrophytes (Luo et al. 2018). For each replicate, benthic materials were collected using a D-frame kick (30 cm wide, 250 $\mu \mathrm{m}$ mesh size $)$ in $30 \times 30 \mathrm{~cm}$ per sample unit $\left(0.09 \mathrm{~m}^{2}\right)$ (Castro et al. 2020). Then, benthic materials were washed in the field using a 500- $\mu \mathrm{m}$ copper mesh sieve. The five subsamples with $0.45 \mathrm{~m}^{2}$ area for each sampling site were handpicked carefully from benthic materials on a porcelain plate and then were preserved with $75 \%$ alcohol. In the laboratory, macroinvertebrates were identified and counted under a stereomicroscope (Olympus; usually for aquatic insects) or a microscope (Imager A2; usually for Oligochaeta and certain Diptera insects). Specimens were identified to possible lowest taxonomic level (usually to genus), and Oligochaeta and Mollusca were identified to the species level using relevant taxonomic keys (Brinkhurst 1986; Epler 2001; Morse et al. 1994; Thorp and Covich 2001; Wiggins 1996; Zhou et al. 2003).

\section{Local environmental variables}

Prior to macroinvertebrate sampling, environmental variables were measured at each sampling site. Water depth (WD) and velocity (Vel) were averaged using a calibrated stick and a LJD-10 flowmeter following a zyg-zag pattern (right-mid-left) in each sampling site, respectively. River width (RW) and turbidity (Tur) were measured by a diastimeter and turbidity meter, respectively. The composition of the substrate by visually estimating the percentages of boulder $(>256 \mathrm{~mm})$, cobble (64-256 mm), pebble $(32-64 \mathrm{~mm})$, gravel $(2-32 \mathrm{~mm})$, sand and silt $(<2 \mathrm{~mm})$ at each sampling site using a 1 $\mathrm{m}^{2}$ grid (Kondolf 1997). Furthermore, we calculated substrate heterogeneity (Div_substrate) from the Simpson index considering the composition of the substrate (Firmiano et al. 2020). Water temperature (WT), pH, dissolved oxygen (DO), and conductivity (Cond) were acquired in the field with a YSI Professional Plus Water Quality Sonde. Besides, $1 \mathrm{~L}$ water sample was collected using an acrylic water sampler and preserved in $4{ }^{\circ} \mathrm{C}$ and then transported to laboratory within $12 \mathrm{~h}$ for further analysis. In laboratory, total nitrogen $(\mathrm{TN})$, total phosphorus (TP), ammonium nitrogen $\left(\mathrm{NH}_{4}{ }^{+}-\mathrm{N}\right)$, 


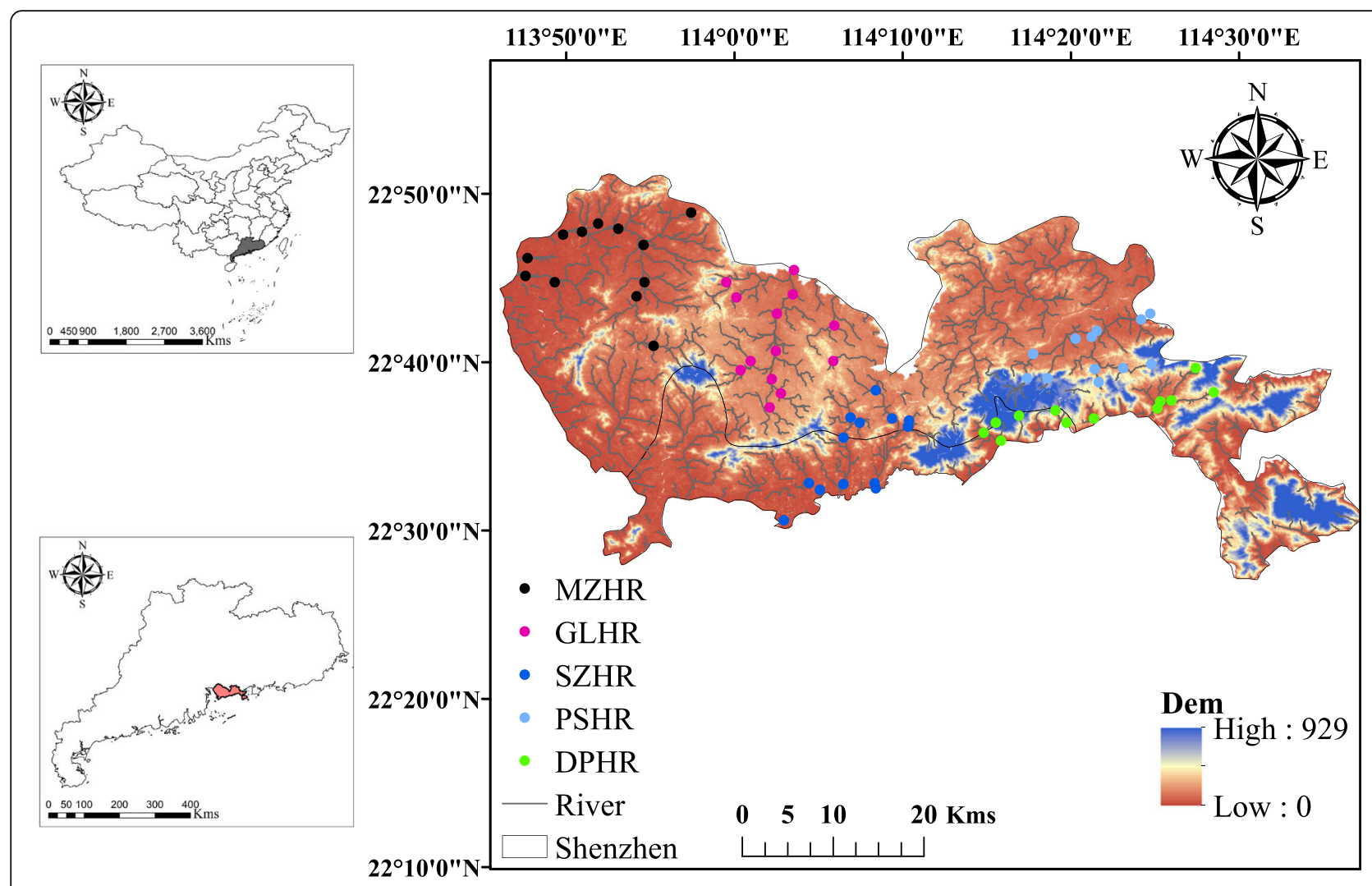

Fig. 1 The study area and sampled watersheds in Shenzhen, South China

chemical demand oxygen $\left(\mathrm{COD}_{\mathrm{Cr}}\right)$, permanganate index (PI), and biochemical oxygen demand over 5 days $\left(\mathrm{BOD}_{5}\right)$ were measured according to standard methods (EPBC 2002).

\section{Spatial factors analysis}

To model the spatial relations of community structure among sampling sites at multiple scales, the principal coordinates of neighbor matrices (PCNM) approach was used to provide spatial factors based on overland distances among sampling sites for further analysis ( $\mathrm{Li}$ et al. 2019). This approach is widely used for modeling spatial structures in biological communities (Legendre and Legendre 2012). We only retained those associated with significant Moran's $I$ and positive eigenvalues because they represent a potential positive autocorrelation between spatial points at different scales (Dray and Legendre 2008). The first larger spatial eigenvalues indicate broad-scale spatial relations between locations and last spatial vectors show smaller scale variation among sites (Borcard et al. 2004; Borcard and Legendre 2002). Eventually, we obtained 25 spatial factors with positive eigenvalues for constrained ordination models. The spatial factors were obtained using the function pcnm in the $\mathrm{R}$ package vegan (Legendre et al. 2013).

\section{Data analysis}

Prior to statistical analysis, local environmental variables (except for $\mathrm{pH}$ ), and biodiversity indices were transformed by $\log (x+1)$ or square root (i.e., proportional data: substrate composition data and the relative abundance of dominant groups) to improve normality. We used Mann-Whitney $U$ tests to detect difference of local environmental variables, the relative abundance of dominant groups, and biodiversity indices across wet and dry seasons. Then, the environmental heterogeneity for each sampling period was examined using the permutational analysis of multivariate dispersions (PERMDISP) (Legendre and Legendre 2012) based on Euclidean distance considering all the standardized environmental variables. Higher average distance indicates the higher environmental heterogeneity (Anderson 2006). Besides, we ran nonmetric multidimensional scaling (NMDS) using the Bray-Curtis similarity distance based on abundance data to distinguish differences in community structures among seasons (Legendre and Legendre 2012). SIMPER analysis was used to identify species that contributed most to community dissimilarity among seasons (Clarke 1993). Besides, one-way analysis of similarities (ANOSIM) with 999 permutations was employed to examine whether taxonomic composition of macroinvertebrate significantly differed among five watersheds (Clarke 1993). 
To elucidate the relative roles of local environmental variables and spatial factors structuring macroinvertebrate community, we employed distance-based redundancy analysis (db-RDA) (Legendre and Anderson 1999) and associated variation partitioning procedures (Legendre and Legendre 2012). Distance-based redundancy analysis (dbRDA) was used to examine the relationships between macroinvertebrate community structure and local environmental variables and spatial factors, respectively. Prior to db-RDA analysis, all environmental variables were scaled to zero mean and unit variance to allow comparisons. Then, we removed highly correlated environmental variables (Spearman $r>0.75$ ) to reduce multicollinearity in the R package Hmisc (Harrell 2016). Both environmental and spatial factors were screened by a forward selection procedure in the $\mathrm{R}$ package adespatial to identify a set of significant factors, respectively (Dray et al. 2017). Then we conducted variation partitioning analysis (Legendre and Legendre 2012) to obtain the pure environmental variables, pure spatial factors, their shared fractions, and unexplained fractions with the varpart function in the $\mathrm{R}$ package Vegan (Oksanen et al. 2017). Additionally, we examined the above fractions by means of the Monte Carlo test with 999 permutations at a significance level of $\alpha=$ 0.05 (Oksanen et al. 2017).
Mann-Whitney $U$ tests analysis was conducted on SPSS version 25.0. The biodiversity index calculation, NMDS analysis, SIMPER analysis, and one-way analysis of similarities (one-way ANOSIM) analysis were conducted using the software PRIMER 6.0 and PERM ANOVA+. Other statistical analysis were performed on $\mathrm{R}$ version 3.6.2 (R Developement Core Team 2018).

\section{Results}

\section{Environmental condition}

In general, except for water temperature (WT), $\mathrm{pH}$, turbidity, river width (RW), ammonium nitrogen $\left(\mathrm{NH}_{4}{ }^{+}-\mathrm{N}\right)$, and total phosphorus (TP), half of the 20 environmental variables were not significantly differed between wet and dry seasons (Table 1). Among them, certain environmental variables related to habitat conditions, such as substrate composition, substrate heterogeneity index, and water depth (WD) were not differed among wet and dry seasons. Specially, wet season had higher water temperature (WT), turbidity, river width $(\mathrm{RW})$, chemical demand oxygen $\left(\mathrm{COD}_{\mathrm{Cr}}\right)$, permanganate index (PI), biochemical oxygen demand over 5 days $\left(\mathrm{BOD}_{5}\right)$, ammonium nitrogen $\left(\mathrm{NH}_{4}{ }^{+}-\mathrm{N}\right)$, while higher values of dissolved oxygen (DO), $\mathrm{pH}$, total nitrogen $(\mathrm{TN})$, conductivity, and velocity were

Table 1 Environmental variables across the 62 sampling sites in the wet and dry seasons. ${ }^{* *} P<0.01$ or ${ }^{*} P<0.05$ indicate the significant difference among seasons based on Mann-Whitney $U$ tests

\begin{tabular}{|c|c|c|c|c|c|c|c|}
\hline & & \multicolumn{2}{|l|}{ Wet season } & \multicolumn{2}{|l|}{ Dry season } & \multirow[t]{2}{*}{$F$} & \multirow[t]{2}{*}{$P$} \\
\hline & & Min-Max & Mean & Min-Max & Mean & & \\
\hline Water temperature $\left({ }^{\circ} \mathrm{C}\right)$ & WT ** & $14.10-34.00$ & $28.57 \pm 3.58$ & $14.30-26.8$ & $21.50 \pm 2.67$ & 126.27 & 0.000 \\
\hline $\mathrm{pH}$ & $\mathrm{pH}^{* *}$ & $6.76-8.76$ & $7.30 \pm 0.33$ & $2.71-9.13$ & $7.72 \pm 0.77$ & 8.01 & 0.005 \\
\hline Dissolved oxygen (mg/L) & DO & $0.13-9.90$ & $5.35 \pm 2.25$ & $1.54-9.41$ & $5.84 \pm 2.06$ & 2.19 & 0.142 \\
\hline Conductivity (s/cm) & Cond & $27.50-1628.00$ & $349.99 \pm 295.36$ & $27.00-6250.00$ & $545.22 \pm 1010.27$ & 1.48 & 0.226 \\
\hline Turbidity (NTU) & Tur ** & $1.14-271.00$ & $38.03 \pm 51.30$ & $0.56-81.90$ & $9.62 \pm 12.54$ & 37.48 & 0.000 \\
\hline River width (m) & $\mathrm{RW} * *$ & $3.00-220.00$ & $40.15 \pm 46.26$ & $0.60-101.00$ & $21.01 \pm 19.81$ & 9.14 & 0.003 \\
\hline Water depth (m) & WD & $0.02-5.00$ & $0.73 \pm 1.06$ & $0.05-3.50$ & $0.47 \pm 0.69$ & 2.97 & 0.088 \\
\hline Velocity $(\mathrm{m} / \mathrm{S})$ & Vel & $0.01-0.81$ & $0.24 \pm 0.18$ & $0.01-0.90$ & $0.25 \pm 0.20$ & 0.17 & 0.681 \\
\hline Div_substrate & Div_substrate & $0.00-0.73$ & $0.23 \pm 0.26$ & $0.00-0.73$ & $0.22 \pm 0.27$ & 0.04 & 0.852 \\
\hline Percentage of boulder & \%Boulder & $0.00-100.00$ & $9.68 \pm 23.73$ & $0.00-100.00$ & $9.92 \pm 24.97$ & 0.00 & 0.952 \\
\hline Percentage of cobble & \%Cobble & $0.00-90.00$ & $11.77 \pm 25.16$ & $0.00-90.00$ & $10.08 \pm 21.93$ & 0.05 & 0.825 \\
\hline Percentage of pebble & \%Pebble & $0.00-85.00$ & $8.87 \pm 17.16$ & $0.00-90.00$ & $9.52 \pm 17.94$ & 0.01 & 0.935 \\
\hline Percentage of gravel & \%Gravel & $0.00-95.00$ & $9.44 \pm 18.36$ & $0.00-95.00$ & $8.26 \pm 18.25$ & 0.39 & 0.531 \\
\hline Percentage of sand and silt & \%Sand and silt & $0.00-100.00$ & $59.92 \pm 44.56$ & $0.00-100.00$ & $62.18 \pm 43.82$ & 0.12 & 0.736 \\
\hline Permanganate index (mg/L) & PI & $0.90-12.30$ & $3.04 \pm 2.09$ & $0.50-5.10$ & $2.56 \pm 1.14$ & 1.85 & 0.176 \\
\hline Chemical oxygen demand (mg/L) & $\mathrm{COD}_{\mathrm{Cr}}$ & $6.00-69.80$ & $13.81 \pm 14.32$ & $5.00-25.00$ & $10.58 \pm 4.99$ & 0.65 & 0.422 \\
\hline Biochemical oxygen demand over 5 days (mg/L) & $\mathrm{BOD}_{5}$ & $0.50-27.30$ & $2.79 \pm 4.75$ & $0.50-5.90$ & $2.13 \pm 1.26$ & 0.03 & 0.859 \\
\hline Ammonium nitrogen (mg/L) & $\mathrm{NH} 4^{+}-\mathrm{N} *$ & $0.03-17.90$ & $2.14 \pm 3.93$ & $0.03-4.10$ & $0.79 \pm 0.83$ & 5.42 & 0.022 \\
\hline Total phosphorus (mg/L) & $\mathrm{TP} *$ & $0.00-1.72$ & $0.27 \pm 0.41$ & $0.01-0.39$ & $0.15 \pm 0.11$ & 4.05 & 0.046 \\
\hline Total nitrogen (mg/L) & TN & $0.13-18.32$ & $4.99 \pm 4.82$ & $0.05-18.22$ & $5.83 \pm 5.04$ & 0.87 & 0.353 \\
\hline
\end{tabular}


detected in the dry season. PERMDISP analysis revealed that there was no significant difference in the variance of the environmental heterogeneity among seasons $(F=0.627 ; P>0.05)$. However, in terms for the variation of the environmental heterogeneity, the dry season (average Euclidean distance: 6.92) was more variable than the wet season (average Euclidean distance: 6.57).

\section{Macroinvertebrate community composition}

A total of 21,714 individuals comprising 158 taxa were collected, belonging to 4 phyla, 8 classes, 20 orders, 74 families, and 141 genera in the entire sampling period. Aquatic insects accounted for $75.32 \%$ (119 taxa), followed by Oligochaeta (19 taxa, 12.03\%), Mollusca (19 taxa, 12.03\%), and Nematoda (1 taxon, 0.63\%). Species with higher occurrence frequency were Limnodrilus sp., Limnodrilus hoffmeisteri, Polypedilum sp., Physa acuta, and Biomphalaria straminea.

In general, 112 and 132 taxa were sampled in the wet and dry seasons, respectively. The top three dominant species in the dry season were Limnodrilus sp. (relative abundance: 8.63\%), Limnodrilus hoffmeisteri (6.98\%), and Limnodrilus claparedeianus (6.21\%), while Chironomus sp. (5.69\%), Polypedilum sp. (5.69\%), and Limnodrilus sp. $(5.45 \%)$ were dominated in the wet season. NMDS analysis showed that there was no significant distinction of macroinvertebrate community composition among seasons (Fig. 2). Only the relative abundance of Mollusca and Odonata were significantly differed among seasons (Supplement Table 1). SIMPER analysis showed that Limnodrilus sp. and Limnodrilus hoffmeisteri were among the most present taxa in both seasons. Other characteristic taxa were Limnodrilus claparedeianus, Branchiura sowerbyi, and Chironomus kiiensis for the

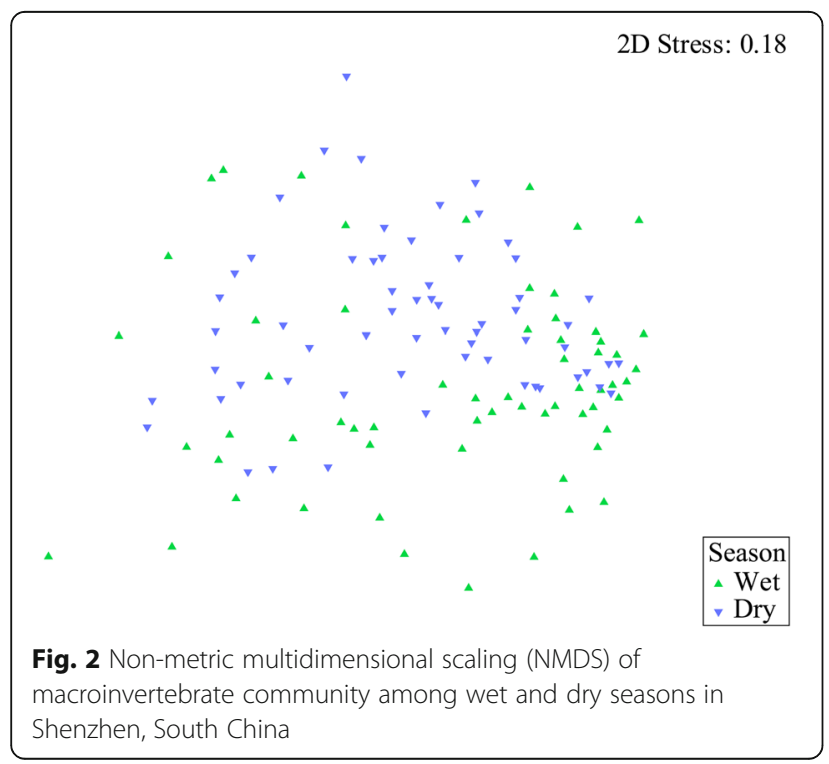

wet season, while Biomphalaria straminea, Chironomus sp., and Polypedilum sp. for the dry season (Table 2).

Spatially, differences in macroinvertebrate composition were evident among the five watersheds (Supplement Figure 1). One-way ANOSIM analysis indicated that all pairwise comparisons of community differed significantly among five watersheds (Global $R: 0.117-0.608, P$ $<0.05$ ), except for GLHR and SZHR (Global $R=0.005$, $P>0.05$ ), PSHR and DPHR (Global $R=0.042, P>0.05$ ), MZHR and GLHR (Global $R=0.044, P>0.05$ ). More specifically, in PSHR and DPHR, aquatic insects (Exclusion of Chironomidae) accounted for $50.81 \%, 53.14 \%$ of the total abundance in the wet and dry seasons, respectively. In MZHR, GLHR, and SZHR, Oligochaeta and Chironomidae constituted $0-100 \%$ of the total abundance with an average value of $71.48 \%$ and $71.36 \%$ in the wet and dry seasons, respectively.

Richness, Simpson index and Shannon-Wiener index differed significantly among seasons, with higher values in the dry season (Fig. 3). In contrast, Evenness did not significantly differ among seasons.

\section{Key environmental and spatial factors affecting community structure}

Forward selection procedure showed that water temperature (WT), water depth (WD), pH, \%sand and silt, and total nitrogen $(\mathrm{TN})$ were significantly associated with the macroinvertebrate communities in the wet season, while water depth (WD), chemical demand oxygen $\left(\mathrm{COD}_{\mathrm{Cr}}\right)$, dissolved oxygen (DO), total phosphorus (TP), and permanganate index (PI) proved to be important in shaping macroinvertebrate communities in the dry season (Table 3; Fig. 4).

Spatial factors analysis based on forward selection procedure showed that PCNM1, PCNM2, PCNM4, and PCNM5 were retained in the wet season, whereas PCNM1, PCNM5, PCNM2, PCNM8, PCNM4, and PCNM28 were retained in the dry season (Table 3; Fig. $4)$.

Table 2 Results of top 5 ranked SIMPER species in both wet and dry seasons

\begin{tabular}{lll}
\hline Taxa & $\begin{array}{l}\text { Wet season } \\
\text { Contribution rate (\%) }\end{array}$ & Dry season \\
\hline Limnodrilus sp. & 25.75 & 13.25 \\
Limnodrilus hoffmeisteri & 17.30 & 11.05 \\
Limnodrilus claparedeianus & 13.79 & \\
Branchiura sowerbyi & 5.82 & 6.56 \\
Biomphalaria straminea & & 14.61 \\
Chironomus sp. & & \\
Chironomus kiiensis & 7.91 & 12.78 \\
Polypedilum sp. & & \\
\hline
\end{tabular}



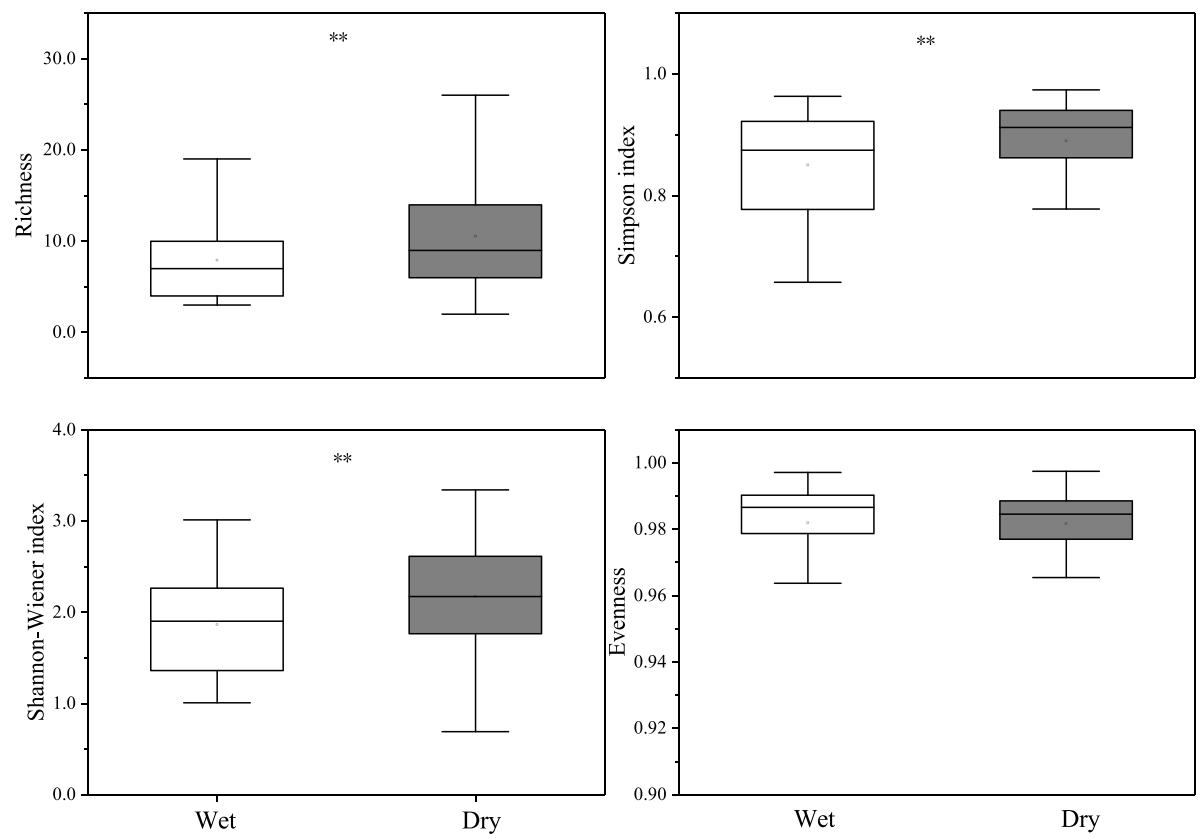

Fig. 3 Richness, Simpson index, Shannon-Wiener index, and Evenness of macroinvertebrate community among wet and dry seasons, respectively. ${ }^{* *} P<0.01$ indicates the significant difference among seasons based on Mann-Whitney $U$ tests

\section{Relative roles of environmental and spatial factors}

Variation partitioning procedure revealed that the pure environmental variables, spatial factors, and their shared effects jointly explained $49 \%$ and $42 \%$ of the community variation in the wet and dry seasons (Fig. 5), respectively. The relative roles of environmental and spatial factors varied slightly among seasons. Specifically, spatial factors explained more of the variations (10\%; Monte Carlo permutations test: $P<0.01)$ compared to environmental variables $(8 \% ; P<0.05)$ in the wet season. Conversely, environmental variables accounted for $9 \%(P<0.01)$ of the community variations than spatial factors $(8 \% ; P<0.01)$ in the dry season. However, the shared fractions (i.e., explained jointly by both environmental variables and spatial factors) accounted for most of the variations, with 31\% ( $P$ $<0.01)$ and $25 \%(P<0.01)$ of the community variations explained in both wet and dry seasons, respectively.

\section{Discussion}

Our results provide the first detailed description of macroinvertebrate community composition and seasonal dynamics in the Shenzhen river networks. There were no

Table 3 Results of forward selection procedure in the db-RDA analysis in both wet and dry seasons

\begin{tabular}{|c|c|c|c|c|c|c|c|c|c|}
\hline & Variable & $\operatorname{Adj} R^{2}$ & Pseudo-F & $P$ & & Variable & Adj $R^{2}$ & Pseudo- $F$ & $P$ \\
\hline \multirow[t]{13}{*}{ Wet season } & \multicolumn{4}{|l|}{ Environmental } & Dry season & \multicolumn{4}{|c|}{ Environmental } \\
\hline & TN & 0.115 & 8.939 & 0.001 & & PI & 0.119 & 9.218 & 0.001 \\
\hline & \%Sand and silt & 0.150 & 3.440 & 0.001 & & WD & 0.136 & 2.208 & 0.010 \\
\hline & WD & 0.172 & 2.569 & 0.001 & & DO & 0.150 & 1.932 & 0.016 \\
\hline & $\mathrm{pH}$ & 0.182 & 1.712 & 0.041 & & $\mathrm{COD}_{\mathrm{Cr}}$ & 0.160 & 1.708 & 0.035 \\
\hline & WT & 0.191 & 1.674 & 0.039 & & TP & 0.171 & 1.772 & 0.024 \\
\hline & \multicolumn{5}{|l|}{ Spatial } & \multicolumn{4}{|l|}{ Spatial } \\
\hline & PCNM1 & 0.100 & 7.760 & 0.001 & & PCNM1 & 0.069 & 5.510 & 0.001 \\
\hline & PCNM2 & 0.137 & 3.561 & 0.001 & & PCNM5 & 0.105 & 3.453 & 0.001 \\
\hline & PCNM4 & 0.169 & 3.295 & 0.001 & & PCNM2 & 0.126 & 2.412 & 0.004 \\
\hline & \multirow[t]{3}{*}{ PCNM5 } & 0.198 & 3.073 & 0.001 & & PCNM8 & 0.147 & 2.409 & 0.005 \\
\hline & & & & & & PCNM4 & 0.164 & 2.197 & 0.006 \\
\hline & & & & & & PCNM28 & 0.179 & 1.958 & 0.013 \\
\hline
\end{tabular}




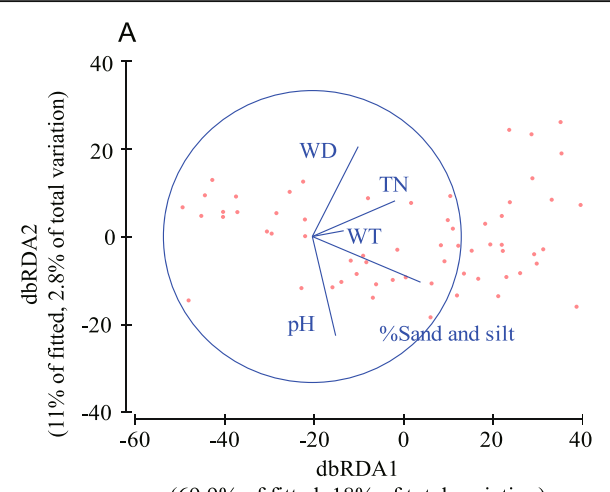

( $69.9 \%$ of fitted, $18 \%$ of total variation)

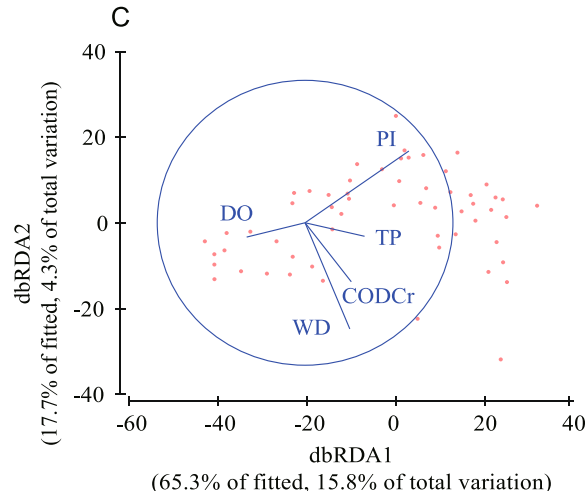

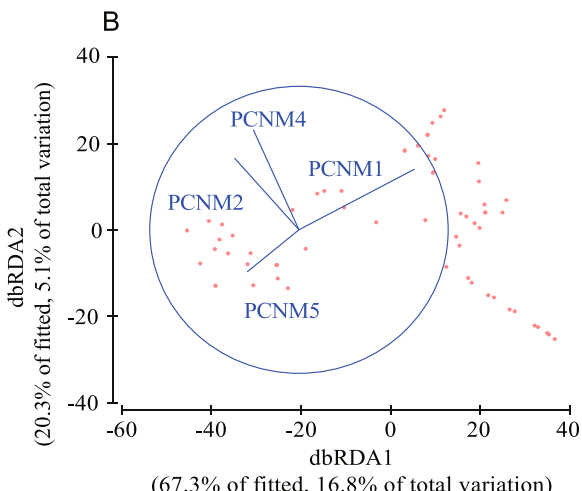

$(67.3 \%$ of fitted, $16.8 \%$ of total variation)

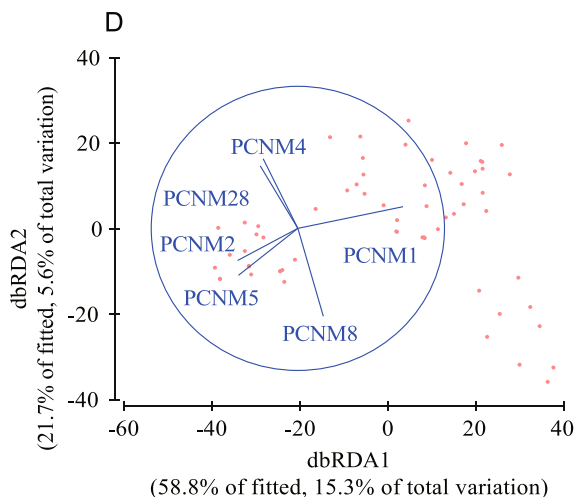

Fig. 4 Distance-based constrained ordination (db-RDA) of macroinvertebrate community for $\mathbf{a}$ environmental variables and $\mathbf{b}$ spatial factors in the wet season, and for $\mathbf{c}$ environmental variables and $\mathbf{d}$ spatial factors in the dry season. The significant environmental and spatial variables were selected based on forward selections $(P<0.05)$

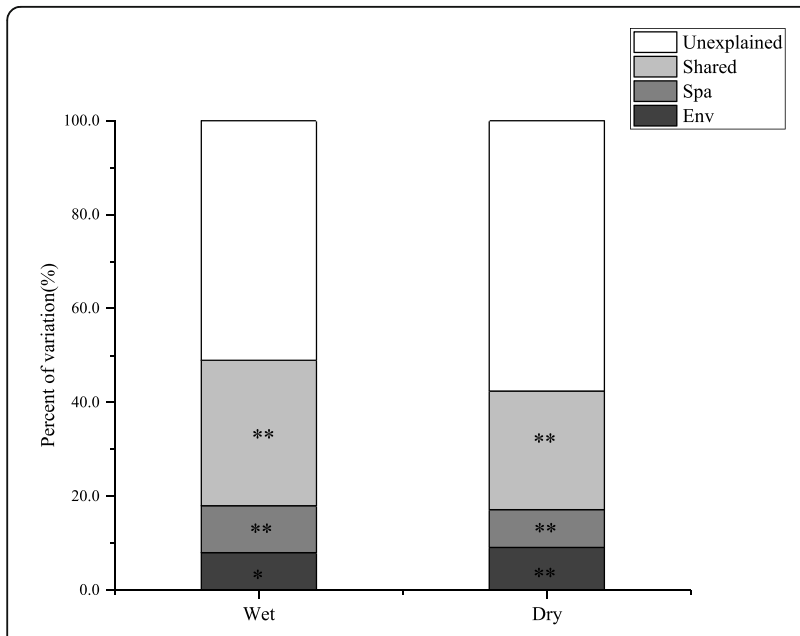

Fig. 5 Variation partitioning of macroinvertebrate metacommunity into pure environmental variables (Env), pure spatial factors (Spa), their shared fractions (Shared), and the unexplained variations among wet and dry seasons. Values represent the adjusted $R^{2}$ values. ${ }^{* *} P<0.01$ or ${ }^{*} P<0.05$ represent significant results based on the Monte Carlo permutations test obvious differences of macroinvertebrate community structure among seasons, which might be owing to relative abundance of tolerant taxa with nonseasonal life history. Further, a novel finding revealed that both environmental filtering and spatial processes equally contributed to the assembly of macroinvertebrate metacommunity. Importantly, our results showed that the identity and explanatory power of environmental and spatial factors differed during the wet and dry seasons.

\section{Mechanisms underlying macroinvertebrate community assembly}

Contradicted to the first prediction, our results detected that macroinvertebrate metacommunity was determined equally by environmental filtering and spatial processes. These findings, however, do not fit well with previous studies that deterministic processes dominated in macroinvertebrate metacommunity assembly in other river ecosystems (He et al. 2020; Li et al. 2020). One possible explanation was that macroinvertebrate communities in this basin are likely to comprise considerable abundance of general tolerant taxa (e.g., Oligochaeta and Chironomidae larva), whose persistence is less sensitive to local environmental conditions (Kim et al. 2008; Rosenberg 
and Resh 1993). Another explanation was that regional habitat homogenization in urban ecosystems would potentially weaken the correspondence of ecological communities to local environments conditions (Bourassa et al. 2017). Besides, one that cannot be ignored was that spatially structured environmental variables contributed more variations for this metacommunity. However, the shared effects of environmental and spatial factors are difficult to interpret. Generally, such shared effects are typical in studies of aquatic metacommunities (Heino et al. 2015; Vilmi et al. 2016). Although we did not identify a dominance of environmental filtering shaping macroinvertebrtae metacommunity, our results revealed that certain local environmental variables related to nutrients (e.g., TN, PI, $\mathrm{COD}_{\mathrm{Cr}}$ ) and physical habitat conditions (e.g., WT and substrate composition) were important for macroinvertebrate communities. These variables were evidenced as the critical factors affecting the relative abundance and occurrence frequency of macroinvertebrate communities (Li et al. 2020; Wang et al. 2020).

Our results revealed that spatial factors also played important roles in explaining variations in macroinvertebrate metacommunity, implying the necessity to consider the dispersal-related processes in routine monitoring and assessment programs. We infer that dispersal limitation generated strong spatial signals in macroinvertebrtae metacommunity. Possible elements contributing to the results include the organism dispersal ability and dispersal constrains (e.g., low-head dam and buildings) (Crook et al. 2015; Csercsa et al. 2018). Spatial factors with large eigenvalues (e.g., PCNM1 and PCNM2) were selected based on a forward selection procedure, indicating that broader scale spatial processes were important in driving the macroinvertebrate metacommunity (Borcard and Legendre 2002). Besides, the dominant species (e.g., Limnodrilus hoffmeisteri and Biomphalaria straminea) in our study were small-bodied aquatic passive groups with limited dispersal ability. Meanwhile, we should realize that these effects would be expected to enhance under the pressure of dispersal constrains. For instance, some low-head dames located in channels would hinder the route of aquatic passive organisms (Wan et al. 2018), while intensive buildings and cultural facilities along the channels would cause negative effects on terrestrial passive and active groups (Urban et al. 2006).

Although the relative importance of environmental and spatial factors varied slightly among seasons, we indeed observed that the identity and explanatory rate of both factors differed between wet and dry seasons. Thus, our results clearly support the prediction that there exist the seasonal shifts of community assembly mechanisms in the study region, and further stress the significance of exploring community assembly mechanisms from the temporal perspective (Li et al. 2020). In terms of the slightly seasonal variation of community assembly, it might be related to a fact that nonsignificant changes in assemblage composition displayed along homogeneous environmental conditions (PERMDISP analysis). One possible explanation was that most macroinvertebrates in urban river ecosystems are generally pollution-tolerant taxa characterized with nonseasonal life cycle (Carlisle and Hawkins 2008). Similarly, a previous relevant study has showed that the seasonal changes in macroinvertebrate communities in the urban river ecosystems were lower than the least-disturbed rivers (Wang et al. 2018).

In line with the second prediction, we found higher biodiversity embodied in the dry than wet seasons. This could be related to higher heterogeneity in microhabitats of macroinvertebrate communities during the period of low water-flow currents and connectivity (Aiello-Lammens et al. 2017; Chen et al. 2019). Our results also detected that stronger environmental filtering structuring community assembly in the dry than wet seasons, implying that deterministic processes dominated in driving community dynamics during the low water-flow conditions (Sarremejane et al. 2017b). This result was reasonable because the strength of environmental filtering is expected to be stronger with increasing environmental harshness during the low water-flow currents period (Boulton 2003; Sarremejane et al. 2017a). In our case, several environmental variables (e.g., $\mathrm{PI}, \mathrm{DO}, \mathrm{COD}_{\mathrm{Cr}}$, and TP) significantly explained the variations in macroinvertebrate communities, thus serve as environmental filters that select for the most resistant/adapted taxa in the regional species pool. Additionally, we found a higher predictive power of spatial factors over metacommunity structures in the wet than dry seasons. A fast recolonization after a flood event may potentially influence the relative contribution of dispersal-related processes on biological communities (Datry et al. 2016). Besides, connectivity among locations would be intensified when flushing water regimes occurred and can act as an excellent proxy for aquatic organism dispersal (Chaparro et al. 2018). Further, one point we cannot ignore is that spatial signal could be enhanced under the massive fly of fledged adult insects in such seasons. However, we only focused on the larvae of macroinvertebrate in the present study, which may ignore the dispersal patterns of fledged adult insects and then limit the representativeness of our results. Thus, different dispersal mode studies of aquatic larvae and adults must be considered in future studies.

It should be noted that the variation partitioning approach employed in our study did not explain all the variations in macroinvertebrate metacommunity, indicating that other community assembly mechanisms might be working in the meantime. These other potential important mechanisms may include species interactions, 
unmeasured environmental variables and historical process (Chase 2003; Heino et al. 2015; Vellend et al. 2014). Although difficult to quantify the potential influences, these factors should also be responsible for variations in metacommunity structure. To better explore the key mechanisms underlying macroinvertebrate metacommunity in subtropical river networks, more effective statistical methodology and experimental consideration through spatial-temporal scale need to be considered.

\section{Implications for the watershed management and biodiversity monitoring}

Urban rivers support significant biodiversity and provide essential ecosystem services (Volker and Kistemann 2011). However, urban rivers have suffered substantial decline of aquatic biodiversity resulting from various anthropogenic stressors (Luo et al. 2018; Wang et al. 2018), but received relatively less attention (Higgins et al. 2019). Thus, unraveling the key driving force underlying community assembly is fundamental to accurate bioassessment, river management and restoration (Heino et al. 2015). Our results suggested that local environmental variables could mediate the macroinvertebrate community by increased nutrients and degraded habitat quality. Consequently, watershed management strategies should focus on improving local abiotic conditions to sustain local biodiversity (Luo et al. 2018; Wang et al. 2018). Furthermore, understanding the community assembly mechanisms should discriminate the signal of environmental filtering from the spatial effects (Heino et al. 2015; $\mathrm{Li}$ et al. 2020). If spatial processes are not considered, the mechanisms underlying community assembly may overestimate the importance of environmental factors (Dale et al. 2002). Our findings revealed that spatial factors and environmental variables play similar roles in influencing macroinvertebrate community. Thus, these findings highlight that watershed management and monitoring should emphasize simultaneously local environmental conditions and dispersal processes to better predict the responses of macroinvertebrate to human stressors. Specifically, given that the mechanisms governing macroinvertebrate community assembly vary among seasons, researchers should also emphasize the idea of long-term investigation at different seasons being necessary to enhance our understanding of their ecological dynamics.

\section{Conclusion}

In summary, our results demonstrated that both environmental and spatial factors equally dedicated to macroinvertebrate metacommunity assembly, implying that the necessity of considering the dispersal-related processes structuring ecological communities in river bioassessment and watershed management. Besides, degraded habitat conditions and water quality (e.g.,
TN, TP, $\mathrm{pH}, \mathrm{COD}_{\mathrm{Cr}}$, and $\mathrm{PI}$ ) were the predominant factors that affected macroinvertebrate communities, indicating the significance and feasibility of improving local abiotic conditions to sustain local biodiversity. Further, our findings revealed that the identity, explanatory power, and relative importance of assembly mechanisms varied among seasons. We thereby argue that one-season snapshot survey is inadequate for quantifying these ecological processes that influence metacommunity dynamics.

\begin{abstract}
Abbreviations
db-RDA: Distance-based redundancy analysis; one-way ANOSIM: One-way analysis of similarities (ANOSIM); NMDS: Non-metric multidimensional scaling analysis; PERMDISP: Permutational analysis of multivariate dispersions; PCNM: Principal coordinates of neighbor matrices; SIMPER: Similarity percentage analysis
\end{abstract}

\section{Supplementary Information}

The online version contains supplementary material available at https://doi. org/10.1186/s13717-021-00297-2.

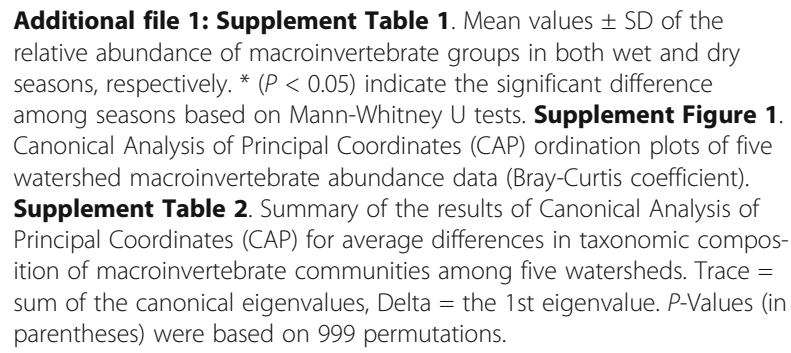

\section{Acknowledgements}

We are grateful to Mr. Lei Liang, Miss. Fanghua Wang, and Dr. Xiao Qu who assisted in field sampling work. We also greatly appreciate the anonymous reviewers and the editors for giving valuable advice for this manuscript.

\section{Authors' contributions}

$Z L, Z X$, and $Y C$ elaborated this research design. $Z L$ conducted the investigation, data analyses, and writing. TZ and ZL conducted the species identification and data processing. ZX, YC, YC, and WW revised the manuscript and provided valuable suggestions. All authors participated in this research.

\section{Funding}

This work was supported by the program "Shenzhen City under the grant of Aquatic Ecological Monitoring and Assessment for Major rivers" (No. 2019-07-233) and Special Foundation for National Science and Technology Basic Research Program of China (grant No. 2019FY101903).

\section{Availability of data and materials}

All data will be available in the data center of Institute of Hydrobiology, Chinese Academy of Sciences (www.ihb.ac.cn) after publication.

\section{Declarations}

Ethics approval and consent to participate Not applicable.

Consent for publication Not applicable. 


\section{Competing interests}

The authors declare that they have no competing interests.

\section{Author details}

${ }^{1}$ Institute of Hydrobiology, Chinese Academy of Sciences, Wuhan 430072, Hubei, China. ${ }^{2}$ University of Chinese Academy of Sciences, Beijing 100049, China. ${ }^{3}$ Central Station for Environmental Monitoring and Assessment, Shenzhen 518049, Guangdong, China.

\section{Received: 1 December 2020 Accepted: 4 April 2021}

\section{Published online: 16 April 2021}

\section{References}

Aiello-Lammens ME, Slingsby JA, Merow C, Mollmann HK, Euston-Brown D, Jones CS, Silander JA (2017) Processes of community assembly in an environmentally heterogeneous, high biodiversity region. Ecography 40(4): 561-576. https://doi.org/10.1111/ecog.01945

Allan JD (2004) Landscapes and riverscapes: the influence of land use on stream ecosystems. Annu Rev Ecol Evol Syst 35(1):257-284. https://doi.org/10.1146/a nnurev.ecolsys.35.120202.110122

Anderson MJ (2006) Distance-based tests for homogeneity of multivariate dispersions. Biometrics 62(1):245-253. https://doi.org/10.1111/j.1541-0420.2 005.00440.x

Barbour MT, Gerritsen J, Snyder BD, Stribling JB (1999) Rapid bioassessment for use in streams and wadeable rivers: periphyton, benthic macroinvertebrates and fish, 2nd edn. US, Environment Protection Agency, Office of Water

Borcard D, Legendre P (2002) All-scale spatial analysis of ecological data by means of principal coordinates of neighbour matrices. Ecol Model 153(1-2): 51-68. https://doi.org/10.1016/S0304-3800(01)00501-4

Borcard D, Legendre P, Avois-Jacquet C, Tuomisto H (2004) Dissecting the spatial structure of ecological data at multiple scales. Ecology 85(7):1826-1832. https://doi.org/10.1890/03-3111

Boulton AJ (2003) Parallels and contrasts in the effects of drought on stream macroinvertebrate assemblages. Freshw Biol 48(7):1173-1185. https://doi. org/10.1046/j.1365-2427.2003.01084.x

Bourassa AL, Fraser L, Beisner BE (2017) Benthic macroinvertebrate and fish metacommunity structure in temperate urban streams. J Urban Ecol 3(1): jux012. https://doi.org/10.1093/jue/jux012

Brinkhurst RO (1986) Guide to the freshwater aquatic microdrile oligochaetes of North America. Canada Spec Publ Fish Aquat Sci 84:1-259

Carlisle DM, Hawkins CP (2008) Land use and the structure of western US stream invertebrate assemblages: predictive models and ecological traits. J N Am Benthol Soc 27(4):986-999. https://doi.org/10.1899/07-176.1

Carvalho JC, Malumbres-Olarte J, Arnedo MA, Crespo LC, Domenech M, Cardoso $P$ (2019) Taxonomic divergence and functional convergence in Iberian spider forest communities: Insights from beta diversity partitioning. J Biogeogr 47: 288-300

Castro DM, da Silva PG, Solar R, Callisto M (2020) Unveiling patterns of taxonomic and functional diversities of stream insects across four spatial scales in the neotropical savanna. Ecol Indic 118:106769. https://doi.org/10.1016/j.ecolind.2 020.106769

Castro DM, Doledec S, Callisto M (2018) Land cover disturbance homogenizes aquatic insect functional structure in neotropical savanna streams. Ecol Indic 84:573-582. https://doi.org/10.1016/j.ecolind.2017.09.030

Chaparro G, Horvath Z, O'Farrell I, Ptacnik R, Hein T (2018) Plankton metacommunities in floodplain wetlands under contrasting hydrological conditions. Freshw Biol 63(4):380-391. https://doi.org/10.1111/fwb.13076

Chase JM (2003) Community assembly: when should history matter? Oecologia 136(4):489-498. https://doi.org/10.1007/s00442-003-1311-7

Chase JM (2007) Drought mediates the importance of stochastic community assembly. Proc Natl Acad Sci U S A 104(44):17430-17434. https://doi.org/10.1 073/pnas.0704350104

Chase JM, Jeliazkov A, Ladouceur E, Viana DS (2020) Biodiversity conservation through the lens of metacommunity ecology. Ann N Y Acad Sci 1469:86-104

Chase JM, Myers JA (2011) Disentangling the importance of ecological niches from stochastic processes across scales. Philos Trans R Soc Lond Ser B Biol Sci 366(1576):2351-2363. https://doi.org/10.1098/rstb.2011.0063

Chave J (2004) Neutral theory and community ecology. Ecol Lett 7(3):241-253. https://doi.org/10.1111/j.1461-0248.2003.00566.x

Chen W, Ren K, Isabwe A, Chen H, Liu M, Yang J (2019) Stochastic processes shape microeukaryotic community assembly in a subtropical river across wet and dry seasons. Microbiome 7(1):138. https://doi.org/10.1186/s40168-0190749-8

Cilleros K, Allard L, Vigouroux R, Brosse S (2017) Disentangling spatial and environmental determinants of fish species richness and assemblage structure in Neotropical rainforest streams. Freshw Biol 62(10):1707-1720. https://doi.org/10.1111/fwb.12981

Clarke KR (1993) Nonparametric multivaria analyses of changes in community structure. Aust J Ecol 18(1):117-143. https://doi.org/10.1111/j.1442-9993.1993. tb00438.x

Cottenie K (2005) Integrating environmental and spatial processes in ecological community dynamics. Ecol Lett 8(11):1175-1182. https://doi.org/10.1111/j.14 61-0248.2005.00820.x

Cottenie K, Michels E, Nuytten N, De Meester L (2003) Zooplankton metacommunity structure: Regional vs. local processes in highly interconnected ponds. Ecology 84(4):991-1000. https://doi.org/10.1890/00129658(2003)084[0991:ZMSRVL]2.0.CO;2

Crook DA, Lowe WH, Allendorf FW, Eros T, Finn DS, Gillanders BM, Hadwen WL, Harrod C, Hermoso V, Jennings S, Kilada RW, Nagelkerken I, Hansen MM, Page TJ, Riginos C, Fry B, Hughes JM (2015) Human effects on ecological connectivity in aquatic ecosystems: Integrating scientific approaches to support management and mitigation. Sci Total Environ 534:52-64. https:// doi.org/10.1016/j.scitotenv.2015.04.034

Csercsa A, Krasznai-K EÁ, Várbíró G, Szivák I, Tóth M, Árva D, Bódis E, Deák C, Mauchart P, Móra A, Erős T, Padisák J, Boda P (2018) Seasonal changes in relative contribution of environmental control and spatial structuring on different dispersal groups of stream macroinvertebrates. Hydrobiologia 828 $101-115$

Dale MRT, Dixon P, Fortin MJ, Legendre P, Myers DE, Rosenberg MS (2002) Conceptual and mathematical relationships among methods for spatial analysis. Ecography 25(5):558-577. https://doi.org/10.1034/j.1600-0587.2002.250506.x

Datry T, Bonada N, Heino J (2016) Towards understanding the organisation of metacommunities in highly dynamic ecological systems. Oikos 125(2):149159. https://doi.org/10.1111/oik.02922

Dray S, Blanchet G, Bordcard D, Guenard G, Jombart T, Larocque G, ... Wagner HH (2017): adespatial: multivariate multiscale spatial analysis. $R$ package version 0. 0-8. Retrieved from https://CRAN.R-project.org/package=adespatial.

Dray S, Legendre P (2008) Testing the species traits-environment relationships: the fourth-corner problem revisited. Ecology 89(12):3400-3412. https://doi. org/10.1890/08-0349.1

EPBC (2002) Standard methods for the monitoring and analysis on water and wastewater, 4th edn. Chinese Environmental Science Press

Epler JH (2001) Identification manual for the larval Chironomidae (Diptera) of North and South Carolina, Version 1.0. Identification manual for the larval chironomidae, p 526

Fernandes IM, Henriques-Silva R, Penha J, Zuanon J, Peres-Neto PR (2014) Spatiotemporal dynamics in a seasonal metacommunity structure is predictable: the case of floodplain-fish communities. Ecography 37(5):464475. https://doi.org/10.1111/j.1600-0587.2013.00527.x

Firmiano KR, Castro DMP, Linares MS, Callisto M (2020) Functional responses of aquatic invertebrates to anthropogenic stressors in riparian zones of Neotropical savanna streams. Sci Total Environ 753:141865

Gál B, Szivák I, Heino J, Schmera D (2019) The effect of urbanization on freshwater macroinvertebrates - knowledge gaps and future research directions. Ecol Indic 104:357-364. https://doi.org/10.1016/j.ecolind.2019.05.012

Harrell FE (2016) Hmisc: Harrell miscellaneous. Available from https://CRAN.Rproject.org/package $=$ Hmisc

He S, Soininen J, Chen K, Wang B (2020) Environmental factors override dispersalrelated factors in shaping diatom and macroinvertebrate communities within stream networks in China. Front Ecol Evol 8:141. https://doi.org/10.3389/ fevo.2020.00141

Heino J, Melo AS, Siqueira T, Soininen J, Valanko S, Bini LM (2015) Metacommunity organisation, spatial extent and dispersal in aquatic systems: patterns, processes and prospects. Freshw Biol 60(5):845-869. https://doi. org/10.1111/fwb.12533

Higgins SL, Thomas F, Goldsmith B, Brooks SJ, Hassall C, Harlow J, Stone D, Völker S, White P (2019) Urban freshwaters, biodiversity, and human health and well-being: Setting an interdisciplinary research agenda. Wiley Interdiscip Rev Water 6:e1339

Hubbell SP, Borda-De-Agua L (2004) The unified neutral theory of biodiversity and biogeography: reply. Ecology 85(11):3175-3178. https://doi.org/10.1890/ 04-0808 
Isabwe A, Yang JR, Wang Y, Liu L, Chen H, Yang J (2018) Community assembly processes underlying phytoplankton and bacterioplankton across a hydrologic change in a human-impacted river. Sci Total Environ 630:658-667. https://doi.org/10.1016/j.scitotenv.2018.02.210

Keddy PA (1992) Assembly and response rules-goals for predictive community ecology. J Veg Sci 3(2):157-164. https://doi.org/10.2307/3235676

Kim B, Lee SE, Song MY, Choi JH, Ahn SM, Lee KS, Cho E, Chon TS, Koh SC (2008) Implementation of artificial neural networks (ANNs) to analysis of inter-taxa communities of benthic microorganisms and macroinvertebrates in a polluted stream. Sci Total Environ 390(1):262-274. https://doi.org/10.1016/j. scitotenv.2007.09.009

Kondolf GM (1997) Application of the pebble count notes on purpose,method and variants. J Am Water Resour Assoc 33:79-87

Legendre P, Anderson MJ (1999) Distance-based redundancy analysis: testing multispecies responses in multifactorial ecological experiments. Ecol Monogr 69(1):1-24. https://doi.org/10.1890/0012-9615(1999)069[0001:DBRATM]2.0.CO;2

Legendre P, Borcard D, Blanchet F, Dray S (2013): PCNM: MEM spatial eigenfunction and principal coordinate analyses. R package version 2.1-2/ r109. Available from: http://R-Forge.R-project.org/projects/sedar/.

Legendre P, Legendre L (2012) Numerical ecology, 3rd English ed. Elsevier

Leibold MA, Holyoak M, Mouquet N, Amarasekare P, Chase JM, Hoopes MF, Holt RD, Shurin JB, Law R, Tilman D, Loreau M, Gonzalez A (2004) The metacommunity concept: a framework for multi-scale community ecology. Ecol Lett 7(7):601-613. https://doi.org/10.1111/j.1461-0248.2004.00608.x

Li Z, Wang J, Liu Z, Meng X, Heino J, Jiang X, Xiong X, Jiang X, Xie Z (2019) Different responses of taxonomic and functional structures of stream macroinvertebrate communities to local stressors and regional factors in a subtropical biodiversity hotspot. Sci Total Environ 655:1288-1300. https://doi. org/10.1016/j.scitotenv.2018.11.222

Li Z, Xing Y, Liu Z, Chen X, Jiang X, Xie Z, Heino J (2020) Seasonal changes in metacommunity assembly mechanisms of benthic macroinvertebrates in a subtropical river basin. Sci Total Environ 729:139046. https://doi.org/10.1016/j. scitotenv.2020.139046

Liu Y, Wang C, Yu Y, Chen Y, Du L, Qu X, Peng W, Zhang M, Gui C (2019) Effect of urban stormwater road runoff of different land use types on an urban river in Shenzhen, China. Water 11(12):2545. https://doi.org/10.3390/w11122545

Logue JB, Mouquet N, Peter H, Hillebrand H, Metacommunity Working G (2011) Empirical approaches to metacommunities: a review and comparison with theory. Trends Ecol Evol 26(9):482-491. https://doi.org/10.1016/j.tree.2011.04.009

Luo K, Hu X, He Q, Wu Z, Cheng H, Hu Z, Mazumder A (2018) Impacts of rapid urbanization on the water quality and macroinvertebrate communities of streams: A case study in Liangjiang New Area, China. Sci Total Environ 621: 1601-1614. https://doi.org/10.1016/j.scitotenv.2017.10.068

Morse JC, Yang L, Tian L (1994) Aquatic insects of China useful for monitoring water quality. Hohai University Press

$\mathrm{Ng}$ CN, Xie YJ, Yu XJ (2011) Measuring the spatio-temporal variation of habitat isolation due to rapid urbanization: a case study of the Shenzhen River crossboundary catchment, China. Landsc Urban Plan 103(1):44-54. https://doi. org/10.1016/j.landurbplan.2011.05.011

Oksanen J, Blanchet FG, Friendly M, Kindt R, Legendre P, McGlinn D, Minchin PR, O'Hara RB, Simpson GL, Solymos P, Stevens MHH, Szoecs E, Wagner H (2017) vegan: community ecology package

Qian Y, Zhou W, Pickett STA, Yu W, Xiong D, Wang W, Jing C (2020) Integrating structure and function: mapping the hierarchical spatial heterogeneity of urban landscapes. Ecol Process 9.59. https://doi.org/10.1186/s13717-020-00266-1

R Developement Core Team (2018) R: a language and environment for statistical computing. R Foundation for Statistical Computing https://www.R-project.org/

Raabe JK, Hightower JE (2014) Assessing distribution of migratory fishes and connectivity following complete and partial dam removals in a North Carolina River. N Am J Fish Manag 34(5):955-969. https://doi.org/10.1080/02 755947.2014.938140

Rosenberg DM, Resh VH (1993) Freshwater biomonitoring and benthic macroinvertebrates, vol i-ix, pp 1-488

Sarremejane R, Cañedo-Argüelles M, Prat N, Mykrä H, Muotka T, Bonada N (2017a) Do metacommunities vary through time? Intermittent rivers as model systems. J Biogeogr 44(12):2752-2763. https://doi.org/10.1111/jbi.13077

Sarremejane R, Mykrä H, Bonada N, Aroviita J, Muotka T (2017b) Habitat connectivity and dispersal ability drive the assembly mechanisms of macroinvertebrate communities in river networks. Freshw Biol 62(6):10731082. https://doi.org/10.1111/fwb.12926
Schmera D, Heino J, Podani J, Erős T, Dolédec S (2016) Functional diversity: a review of methodology and current knowledge in freshwater macroinvertebrate research. Hydrobiologia 787:27-44

Shenzhen Climate Bulletin (2019) http://weather.sz.gov.cn/xingxigongkai/ tongjishuju/shujujiedu/

Shenzhen Statistical Yearbook (2019) http://tjj.sz.gov.cn/zwgk/zfxxgkml/tjsj/tjnj/

Shu W, Wang P, Zhang H, Ding M, Wu B (2020) Seasonal and spatial distribution and assembly processes of bacterioplankton communities in a subtropical urban river. FEMS Microbiol Ecol 96(9):fiaa154. https://doi.org/10.1093/ femsec/fiaa154

Thorp JP, Covich MP (2001) Ecology and Classification of North American freshwater invertebrates, 2nd edn. Academic Press, pp 1-1073

Tonkin JD, Stoll S, Jähnig SC, Haase P (2016) Elements of metacommunity structure of river and riparian assemblages: communities, taxonomic groups and deconstructed trait groups. Ecol Complex 25:35-43. https://doi.org/10.1 016/j.ecocom.2015.12.002

Urban MC, Skelly DK, Burchsted D, Price W, Lowry S (2006) Stream communities across a rural-urban landscape gradient. Divers Distrib 12(4):337-350. https:// doi.org/10.1111/j.1366-9516.2005.00226.x

Vanschoenwinkel B, Waterkeyn A, Jocqué M, Boven L, Seaman M, Brendonck L (2010) Species sorting in space and time-the impact of disturbance regime on community assembly in a temporary pool metacommunity. J N Am Benthol Soc 29(4):1267-1278. https://doi.org/10.1899/09-114.1

Vellend M, Srivastava DS, Anderson KM, Brown CD, Jankowski JE, Kleynhans EJ, Kraft NJB, Letaw AD, Macdonald AAM, Maclean JE, Myers-Smith IH, Norris AR, Xue X (2014) Assessing the relative importance of neutral stochasticity in ecological communities. Oikos 123(12):1420-1430. https://doi.org/10.1111/oik.01493

Vilmi A, Karjalainen SM, Hellsten S, Heino J (2016) Bioassessment in a metacommunity context: Are diatom communities structured solely by species sorting? Ecol Indic 62:86-94. https://doi.org/10.1016/j.ecolind.2015.11.043

Volker S, Kistemann T (2011) The impact of blue space on human health and wellbeing - Salutogenetic health effects of inland surface waters: a review. Int J Hyg Environ Health 214(6):449-460. https://doi.org/10.1016/j.ijheh.2011.05.001

Wan Y, Yang JQ, Zou DW, Li JJ, Qiao YJ, An SQ, Leng X (2018) Effects of multiple dams on the metacommunity structure of stream macroinvertebrates. Mar Freshw Res 69(5):721. https://doi.org/10.1071/MF17159

Wang J, Hu J, Tang T, Heino J, Jiang X, Li Z, Xie Z (2020) Seasonal shifts in the assembly dynamics of benthic macroinvertebrate and diatom communities in a subtropical river. Ecol Evol 10(2):692-704. https://doi.org/10.1002/ece3.5904

Wang Q, Ross-Nickoll M, Wu D, Deng W, Wang Z, Yuan X, Zhang Y (2018) Impervious area percentage predicated influence of rapid urbanization on macroinvertebrate communities in a southwest China river system. Sci Total Environ 627:104-117. https://doi.org/10.1016/j.scitotenv.2018.01.231

Wiggins GB (1996) Larvae of the North American caddisfly genera (Trichoptera), 2nd edn. University of Toronto Press, pp 1-457. https://doi.org/10.3138/ 9781442623606

Zhou C, Gui H, Zhou K (2003) Larval key to families of Ephemeroptera from China (Insecta). J Nanjing Normal Univ (Natural Science Edition) 26(2):65-68

\section{Publisher's Note}

Springer Nature remains neutral with regard to jurisdictional claims in published maps and institutional affiliations.

\section{Submit your manuscript to a SpringerOpen ${ }^{\circ}$ journal and benefit from:}

- Convenient online submission

- Rigorous peer review

- Open access: articles freely available online

- High visibility within the field

- Retaining the copyright to your article

Submit your next manuscript at $>$ springeropen.com 